\title{
An Overview of Approaches to the Study of Public Policy
}

\author{
Prof. Adam A. Anyebe \\ Department of Public Administration, Faculty of Administration, Ahmadu Bello University, Zaria \\ *Corresponding Author: Prof. Adam A. Anyebe, Department of Public Administration, Faculty of \\ Administration, Ahmadu Bello University, Zaria
}

\begin{abstract}
Political and social scientists have developed many theories, models and approaches for analysing policy-making. The theoretical approaches include elite theory, group theory, political systems theory and institutionalism, policy output analysis, incremental theory and rational-choice theory which are primarily concerned with public policy-making as a process. This paper therefore, attempts to examine each theory, pointing out its strengths and limitations. The study relied heavily on secondary sources for data collection. The paper reveals that one cannot authoritatively see which of these theoretical approaches is the best or the most satisfactory as each approach focuses on different aspects of policy-making, and this seems more useful for understanding some situations or events than others. It is, therefore, wise not to be bound too dogmatically to one approach. A good rule for the policy maker is to be eclectic and flexible, and to draw from theories that seem most useful for the satisfactory and fair-minded description and explanation of policies. The objective explanation of political behaviour rather than the validation of one's preferred theoretical approach should be the goal of political inquiry. Each of the theories discussed, if drawn upon skilfully and selectively, can contribute to a better understanding of policy-making.
\end{abstract}

Keywords: Public Policy, Group Theory, Elite Theory, Incremental Theory, Rational-Choice Theory, Systems Theory

\section{INTRODUCTION}

We usually view policy as designating behaviour of some actor or set of actors, such as an official, or government agency, or legislator, in area of activity such as public enterprise or poverty reduction. Public policy also may be seen as whatever a government chooses to do or not to do. Such definition may be sufficient for ordinary discourse, but definitely inadequate for a systematic analysis of public policy, hence a more precise definition is needed to structure our thinking and to facilitate effective communication with one another (Anderson, 1997). Nonetheless, there is still common reference point by all users of various disciplines. It is used mainly in reference to what government does in order to meet the needs of the citizenry.

Public policy may refer to what government intends to do to achieve certain goals. This definition makes public policy look like a mere decision. That is to say that mere declaration of intentions, wishes, principles, or expression of desires cannot be called public policy. Public policy should mean actual resource allocation presented by projects and programmes designed to respond to perceived public problems and challenges requiring government action for their solution. That is, it should mean hard patterns of resource allocation presented by projects and programmes designed to respond to perceived public demands. This conception of public policy can be identified with a political scientist, James E. Anderson who defines policy as a relatively stable, purposive course of action followed by an actor or set of actors in dealing with a problem or a matter of concern (Anderson, 1997). This statement focuses on what is actually done instead of what is only proposed or intended, and it differentiates a policy from mere decision, which is essentially a choice among competing alternatives. Public policy, therefore, is that policy developed and implemented by government agency and officials, though non-state actors and factors may influence its process.

The scope and content of public policies will obviously vary from country to country, depending on the system of government and ideology in force in that country. In most developing countries where so much is expected of government and where government actions transcend virtually all aspects of 
life of the citizens, the range of public policies is usually very broad and almost unlimited. This study therefore, attempted to overview approaches to the study of public policy, highlighting the strengths and limitations of each approach.

\section{Method Of Data Collection}

The data used in the study were collected from government publications such as the Constitution of the Federal Republic of Nigeria, 1999 as amended, journals, internet materials and other relevant government publications.

\section{RESULTS AND DisCUSSION}

Political and social scientists have developed many theories, models and approaches for analysing policy-making. Indeed public administrators have often displayed more facilities and verve for theorising about public-policy making than for actually studying policy and policy making process. Nonetheless, theories are needed to guide the study of public policy, to facilitate communication, and to suggest possible explanation for policy action. They are useful to the extent that they direct our attention to important political phenomenon, help clarify and organise our thinking, and suggest explanations for political activities such as public policies. Strengths and limitations are pointed out as the discussion proceeds. The theoretical approaches include elite theory, group theory, political systems theory and institutionalism, policy output analysis, incremental theory and rational-choice theory which are primarily concerned with public policy-making as a process. Each of these theories is briefly discussed.

\subsection{Elite Theory}

This model posits that, contrary to the belief that pluralism has in-built mechanism for ensuring equity in the share of power and influence in society, in reality public policy is by and large the mirror image of the ruling elite's interest. Vilfredo Pareto in his book „Mind and Society argues that persons of ability actively seek to confirm and aggrandise their social position. The elite group is divided into governing and non-governing ones. These few that possess unique qualities such as skills, material wealth, cunning and intelligence have the rights to supreme leadership, while the bulk of the population (masses) is destined to be ruled. Thus social classes are formed (Obi et al, 2008).

In his own work entitled „The Ruling Class ${ }^{e}$ Gaetano Mosca, an Italian sociologist, posited that in the history of man, only one type of government had existed which was Oligarchy. He argued that:

In all societies, right from societies that are very meagrely developed and have barely attained the dawn of civilization down to the most advanced and powerful societies- two classes of people appear, a class that rules and a class that is ruled. The first class, always the less numerous, performs all political functions, monopolises power and enjoys the advantages that power brings, whereas the second, the more numerous class is directed and controlled by the first, in a manner that is now more or less legal, now more or less arbitrary and violent and supplies the first, in appearance at least, with the instrumentalities that are essential to the vitality of political organism. (Mosca, 1939).

Mosca was also of the belief that apart from the fact that the minority is usually composed of superior individuals, the fact of their being few helps them to be more organised. He also wrote that the larger the political community, the smaller will be the proportion of the minority and the more difficult it will be for the majority to organise for reaction against the minority.

Mosca went further to say that in the circulation of elites, once the ruling class loses its aptitude to command and exercise political control, and those outside the ruling class, develop its aptitude, they will overthrow the old class and take over. He also believes so much in role of the middle class in a political system. He labels them the 'sub-elite'. He thus argues that the stability of any political organism depends on the level of morality, intelligence and activity that this second stratum has attained. He believes the policies of ruling class are made in the interests of the class, but couched in a moral and legal garb. He believes more in moral cohesion than physical force. 
Mosca went further to describe the virtues of the ruling class as a representative of the elite in the following words:

In addition to the great advantage accruing to them from the fact of being organised, ruling minorities are usually so committed that the individuals who make them up are distinguished from the mass of the governed by qualities that give them a certain material, intellectual or even moral superiority; or else they are the heirs of individuals who possessed such qualities. In other words, members of a ruling minority regularly have some attribute, real or apparent, which is highly esteemed and very influential in the society in which they live (Mosca,1939: 53).

Approached from perspectives of elite theory, public policy can be regarded as reflecting the values and preferences of a governing elite. The essential argument of elite theory is that public policy is not determined by the demands and actions of the people or the masses but rather by ruling elite whose preferences are carried into effect by political officials and agencies. In other words, according to this theory, the elite simply believe that they alone have the ability to determine the policies to promote the welfare of the masses and implement them. Thus policies flow downward from the elite to the masses. The policies made by the elites reflect elite values and prefer status quo to radical changes. Professors Thomas Dye and Harmon Zeigler provide a summary of elite theory:

$>$ Society is divided into the few who have power and the many who do not have. Only small number persons allocate values for society; the masses do not decide public policy

$>$ The few who govern are not typical of the masses who are governed. Elite are drawn disproportionately from upper socio-economic strata of society.

$>$ The movement of non-elites to elite positions must be slow and continuous to maintain stability and avoid revolution. Only non-elites who have accepted the basic elite consensus can be admitted to governing circles.

$>$ Elites share a consensus on the basic values of the social system and the preservations of the system.

$>$ Public policy does not reflect demands of the masses but rather the prevailing values of the elite. Changes in public policy will be incremental rather than revolutionary. Incremental changes permit responses to events that threaten a social system with a minimum of alteration or dislocation of the system.

$>$ Active elites are subject to relatively little direct influence from apathetic masses. Elites influence masses more than the masses influence elites (Dye and Zeigler, 1990)

The above assumptions presuppose that if the government is committed to serving the interest of the masses it must do something about curtailing the excesses of the elite. This could be done by adopting a participatory approach to policy making, involving all key stakeholders, thereby subduing the undue manipulation of the elite. Once this feat is achieved the structure of the society would move away from the hour-glass shape to a more horizontal or flatter shape. However, for this objective to be achieved the formation of the government itself has to first be devoid of elite manipulation in terms of elections and appointment to political positions.

The essence of this model is that public policy is determined by the ruling elite and carried into effect by public bureaucrats and agencies. Dye (1981) summarises the implication of this theory as indicating that public policy reflects elite values, serves elite ends, and is a product of the elite. The corollary of this assumption is that the general citizenry or the masses are apathetic and ill-informed and do not determine or influence policy through their demands or actions.

So stated, elite theory is a provocative theory of policy formation because policy here, is the product of elites, reflecting their values and serving their ends, one of which may be a desire to provide in some way for the welfare of the masses. One other limitation of this model is that it assumes a highly structured and stratified society. In structurally diffused societies, elite formation and therefore, elite values and elite identity is relatively undeveloped. For example, in Nigeria, it is easy to find members 
of an elite group sharing opposing values and identifying more strongly with say, the aspirations of the masses of their ethnic areas or religious groupings than with the aspirations of their fellow elites. Thus, ethnic and religious values rather than elite interest in that case, may influence elite preferences when certain policy issues are under consideration.

According to Nicholas Henry, this model may be the most germane to Public administrators. The elite model has found more adherents among sociologists than among political scientists. Domhoff (1990) has long argued, however, that there is an American upper class based on the ownership and control of large corporations which is infact a governing class.

\subsection{Group Theory}

According to the group theory of politics, public policy is the product of the group struggle. What may be called public policy is the equilibrium reached in this group struggle at any given moment, and it represents a balance which the contending factions or groups constantly strive to win in their favour. Many public polices do reflect the activities of groups (Anderson, 1997). This means that this theory attempts to analyse how each of the various groups in a society tries to influence public policy to its advantage at the policy formulation level.

In other words, the central practice of this model is that interaction among groups is a critical ingredient in politics. Public policy is thus a temporary point of compromise reached in the course of competition between mosaics of numerous interest groups with cross-cutting membership. The ability of the group that is favoured at one point to sustain its gain depends on its power to counteract the powers of other groups that would make efforts to tilt decisions to their favour. It is this type of competition between groups that determine pattern of allocation of societal resources (Enemuo, 1999: 24). The locus of power in the society changes from time to time, depending upon the group that succeeds in exerting its own supremacy over the others. Accordingly, the power to determine policy direction changes with the changes in the fortunes of each or a combination of these groups. It is in appreciating the fluidity of power base in society that Latham contends that what we regard as public policy is in reality a temporary equilibrium reached in the course of the inter-group struggle (Latham, 1965). As soon as the equilibrium point is altered in the favour of new groups another policy will emerge or the old policy will be modified. Politics in essence entails a dynamic equilibrium created by the struggle between different groups. In Latham"s opinion the legislature acts only as a referee to the inter-group struggle and it ratifies the victories of the successful coalitions, as well as record the terms of the surrender, compromises, and conquest in the form of statutes or Bills (Latham, 1965).

Since the power to dominate policy decision is dependent on group solidarity and power, the dynamics of the policy process is expected to be more vibrant and fierce in plural societies than in homogenous ones. In such societies the ability of a group to tilt the policy to its favour depends on a number of factors, prominent among which are:

$>$ Wealth

$>$ Organisational skill

$>$ Leadership quality

$>$ Bargaining skill

$>$ Access to decision-makers or in Nigerian parlance "connection

$>$ A modicum of luck

Wealth is essential because political mobilisation is resource absorbing. All over the world, even in the most democratic societies, politics involves a lot of expenditure; as such only the wealthy can afford to mobilise the electorate and those in authority to tilt decisions in their favour. Wealth alone without organisational skills will render a group ineffective. It is the ability to conceive of ideas and get people to subscribe to such ideas that can get a group or person to succeed in tilting policy decision in its favour. In contemporary period, organisational skill requires the tack of bringing all stakeholders on board in the process of policy decision. For example, the group that attempts to mobilise the public in order to push its ideas would have to be tactful in main-streaming various interest groups such as the women, youth, professional groups and, in some cases, traditional rulers. Central to organisation ability in mobilising the public is leadership. Without a concrete rallying focal 
point a wealthy group, with a sprinkling of persons with diffuse organisational skills, will fail woefully in pushing its agenda in the policy process. But, when there is a strong leadership, especially a charismatic on the group can succeed in pushing its agenda through with relative ease. One of the virtues of good leadership is the ability to bargain successfully even in a turbulent environment. A group would thus succeed in pushing its agenda through the parliament when it has strong bargaining skill. The power of lobby is often complemented by the degree of visibility of the lobbyist. Persons that are well known and respected in society could easily influence decision makers to support their ideas in parliament. In the Nigerian parlance it is said that those with proper "connection" with those in the corridor of power could easily get their request granted by the legislators. The connection could be political, economic or socio-cultural in the form of ex-school mates, same ethnic group or religious affiliation.

Dahl observes that the good thing about pluralism is that no single group has monopoly over all these resources (Anderson, 1997). The equilibrium point will thus continue to shift position as different groups manipulate these resources to get public policies to their favour, either singly or in concert with other groups that share common interest with them. Coalition building, compromises, trading of favour and conflicts among groups are the key tactics used in the struggle. In this situation the majority or more dominant group will have its way but the minority or less dominant group for the moment will have their say. The struggle will continue without rancor. This is the virtue of democracy, as conceived in the Western world and subscribed to by Dahl. In reality however, especially in Africa and specifically in Nigeria, some groups could hold on to power perpetually and block all conceivable possibility of weaker groups from taking the full advantage offered by democracy. Those in privileged positions either because of their professional background such as the military or business class, or through hereditary entitlement to leadership (traditional rulers) tend to dominate the policy-making process. By doing they succeed in ring-fencing themselves within the enclave of power and prevent other groups from gaining access to it.

The group theory has been crticised on the following grounds:

$>$ First, the group theorists did not really define in clear terms what they mean by the two key concepts in the analysis; group and interests. Thus, while Bentley sees groups as a relation between men, a process of adding man to man, Truman defines it as any collection of individuals who have some characteristic in common. None of these definitions clearly tells us what a group that is really relevant to politics and decision making is.

$>$ Second, the theory was so concerned with the role of groups that it leaves out the individuals and society in their analysis. While not disputing the fact that politics is a struggle between and among groups, one can also not forget that the role of particular individuals is a very important variable. This is particularly important in third world countries, where one-man dictatorship has proved that an individual could indeed hold a whole country to ransom and dictate what happens mostly after decimating all competing groups. Also, the role of the society in this competition for power is completely left out which is a defect.

\subsection{Systems Theory}

The systems theory in political science owes its origin to David Easton who is reputed to be the scholar that attempted to analyse politics from the perspective of systems in his famous work political system $^{\text {ee }}$ which appeared in 1953. His work which was regarded as the foundation of the behaviourist revolution in political science outlined eight major characteristics. He described the characteristics as the intellectual foundation stone of behaviourism which are regularities, verification, techniques, quantification, values, systemisation, pure science, and integration.

According to Varma, Easton was able to distill these characteristics from a range of behavioural literature and while they are not unique to systems theory, they do form the basis for the natural linkage between systems thinking and behaviourism (Obi et al, 2008).

In other words, a political system may be that system of interactions in any society through which authoritative allocations are made and implemented in the form of policies and decisions. Public policy may also be seen as a political system's response to demands arising from its environment. The political system, as Easton defines it, comprises those identifiable and interrelated institutions and activities (what we usually think of as government institutions and political processes) in a society 
that make authoritative allocations of values (decisions) that are binding on society (Anderson, 1997). This environment consists of all phenomena-the social system, the economic system, the biological setting - that are external to the boundaries of the political system. Thus, at least analytically one can separate the political system from all the other components of a society (Easton, 1965).

If the open system model is applied in public policy analysis the issues to reflect on include the nature of the components of the system which constitute the sub-systems, and the outside components that impinge on the system directly, which is referred to supra-system (Dlakwa, 2004). Inputs into the political system from the environment consist of demands and supports. Demands are usually the claims for action that individuals and groups make to satisfy their interest and values. Support is rendered when groups and individuals abide by election results, pay taxes, obey laws, and otherwise accept decisions and actions taken by the political system in response to demands. The amount of support for a political system indicates the extent to which it is regarded as legitimate, or as authoritative and binding on its citizens.

On the other hand, outputs of the political system include laws, rules, judicial decisions, and the like. Regarded as the authoritative allocations of values, they constitute public policy. The concept of feedback indicates that public policies (or outputs) made at a given time may subsequently alter the environment and the demands arising therefrom, as well as the character of the political system itself. Policy outputs may produce new demands, which lead to further outputs, and so on in a never-ending flow of public policy.

On the whole, this model applies systems theory to the policy-making process. In simple words, according to this model, the political system receives inputs from its environment and converts them into outputs. The inputs are in the form of demands from groups or individuals for specific policy outcomes. The policy outcomes take the form of determination of societal values and allocation of resources. A feedback loop exists by which the outputs alter the future inputs. This model thus relies on concepts of information theory.

In other words, systems theory conceives public policy as the response of the political system to demands from its environment. The political system consists of those institutions that make authoritative allocation of values binding on the society as a whole. The environment of the political system consists of those institutions found in the economic, social, cultural and international systems which shape political process and whose activities are influenced by the political system. Using systems approach, it is assumed that a state of mutual causation exists between public policy and environmental variables (Abdulsalami, 1987).

The usefulness of the systems theory in studying public policy is limited by its highly general and abstract nature. It does not, moreover, say much about the procedures and processes by which decisions are made and policy is developed within the „black box" called the political system. Indeed, systems theory results are sometimes characterised as input-output studies. Nonetheless, this approach can be helpful in organising inquiry into policy formation, it also alerts us to some important facets of the political process, such as these: how do inputs from the environment affect the content of public policy and the operation of the political system? How in turn does public policy affect the environment and the subsequent demands for policy actions? How well is the political system able to convert demands into public policy and preserve itself over time (Anderson, 1997).

\subsection{Institutional Theory}

One of the oldest concerns of political science and public administration is the study of government institutions since political life generally revolves around them. These institutions include legislatures, executives and judiciary; and public policy is authoritatively formulated and executed by them.

Traditionally, the institutional approach concentrates on describing the more formal and legal aspects of government institutions: their formal structure, legal powers, procedural rules, and functions. Formal relationships with other institutions might also be considered, such as legislative-executive relations. Usually, little was done to explain how institutions operated as opposed to how they were supposed to operated, to analyse public policies produced by the institutions and to discover the relationships between institutional structure and public policies.

Subsequently, social scientists turned their attention in teaching and research to the political processes within government or political institutions, concentrating on the behaviour of participants in the process and on political realities rather than formalism. In the study of legislators, attention shifted 
from simply describing the legislature as an institution to analysing and explaining its operation over time, from its static to its dynamic aspects. Thus, in the academic curriculum the course on the legislature usually came to be about the legislative process.

Institutionalism, with its emphasis on the formal or structural aspects of institutions can nonetheless be usefully employed in policy analysis. An institution is, in part, a set of regularised patterns of human behaviour that persist over time and perform some significant social function. It is their differing patterns of behaviour that usually distinguish courts from legislatures, from administrative agencies, and so on. These regularised patter ns of behaviour, which are usually called rules or structures, can affect decision-making and the content of public policy. Rules and structural arrangements are usually not neutral in their effects; rather, they tend to favour some interest in society over others and some policy results over others.

Using this approach in Nigeria at the national level, the primary institutions that would be the focus of policy analysis are invariably the legislative body, the executive and the courts. In developing countries like Nigeria where we are still at a relatively low level of constitutional development, these institutions especially the first two, may take varying forms, depending on the regime in power. During the Second Republic when a democratically elected regime was in power the institutions were the National Assembly, the Federal Executive Council and the Federal Courts. However, during military regimes, Supreme Military Council or Armed Forces Ruling Council was the legislative body, and the Council of Ministers was the executive. By this approach, it is taken for granted that the politics of Nigeria revolves around these institutions and therefore, an understanding of public policy in Nigeria requires a study of the constitution, operation and relationships among these institutions.

In sum, institutional structures, arrangements, and procedures often have important consequences for the adoption and content of public policies. They provide part of the context for policy-making, which must be considered along with the more dynamic aspects of politics, such as political parties, groups, and public opinion in policy study. By itself, however, institutional theory can provide only partial explanations of policy.

This model studies the official structures and functions of government departments and institutions in an attempt to learn how public policy takes shape. It focuses on the organisation chart of government. However, this model has shown little concern about the connections between a department and the public policy emanating from it. While the systems approach is dynamic and process-oriented, institutionalist approach is more static and formalistic. As the behaviouralist movement took hold within political science during the 1950s and 1960s institutional studies of the policy process were gradually replaced by the empirical model. Based on the behaviouralist principles the empirical research makes an attempt to know how government institutions actually function. The empirical research makes use of experimental and quasi-experimental procedures to identify policy effects as precisely as possible. However, as Thomas Dye points out, the institutional approach can yield benefits to those concerned with how public policy takes shape (Naidu, 2006).It is more useful to view these models as complementary rather than competitive tools for the study of public policymaking as a process.

\subsection{Incremental Theory}

Incremental decisions involve limited changes or additions to existing policies, such as a smallpercentage increase in ministry of education's budget or a modest tightening of eligibility requirements for federal scholarship. According to this approach, the policy-makers examine a limited number of policy alternatives and implement change in a series of small steps. It may be noted that each of the alternatives available to the policy-maker represents only a small change in the status quo. This approach recognises the less than ideal circumstances under which administrators must make policies. There are very real limits of time, brains money etc. on administrator's ability to understand complex problems and make different policies about them. Because of these limitations, the policymakers, though they try to be rational, accept the past policies that satisfy them as legitimate and suffice to deal with the issue.

Charles Lindblom is associated with this model. He contends that incrementalism is the typical policy-making in pluralist societies such as the United States and even Nigeria. Decisions and policies are the product of give and take and mutual consent among numerous participants in the policy 
process. Incrementalism is politically expedient because it is easier to reach agreement when the matters in dispute among various groups are only limited modifications of existing programmes rather than policy issues of great magnitude or of an all-or-nothing character. Because policy makers operate under conditions of uncertainty about the future consequences of their actions, incremental decisions tend to reduce the risks and cost of uncertainty. Incrementalism is also realistic because it recorgnises that policy makers lack the time, intelligence, and other resources needed to engage in comprehensive analysis of all alternative solutions to existing problems. Moreover, people are essentially pragmatic seeking not always a single best way to deal with a problem but, more modestly, something that would work. In a nut-shell, incrementalism utilises limited analysis to yield limited, practical, acceptable decisions.

According to Simon (1957) who accepts Linblom"es theory, rather than being comprehensive in our decision-making, says we often engage in a ,successive limited comparison "e of issues and facts at our disposal. Similarly, rather than insisting on getting the most optimal results we often end up in satisficing. Simon "es satisficing theory, which is part of the genre of incremental, is based on what he terms „bounded rationality". In essence, man is limited by his incapacity to handle satisfactorily multiple tasks concurrently. According to him:

Our world is a world of limited, serial information processors dealing with complexity that for all practical purposes is infinite in comparison with their information powers. It is a world peopled by creatures of bounded rationality. Because we cannot simultaneously attend to everything that is potentially relevant, we must have processes that determine the focus of attention (Simon, 1957).

Several criticisms have greeted incrementalism. One is that it is too conservative, to focused on the current order; hence, it is a barrier to innovation, which is often necessary for effective policies. Another is that in crisis situations, incrementalism provides no guidelines for handling the tasks of decisions. Third, geared as it is to past actions and existing programmes and to limited changes in them, incrementalism may discourage the search for or use of other readily available alternatives (Anderson, 1997). Fourth, incrementalism does not eliminate the need for theory in policy-making, are some of the more enthusiastic advocates contend. Unless changes in policy are to be made simply at random or arbitrarily, some theory is needed to guide the action and to indicate the likely effect of proposed changes (Hayes, 1992:2). Non-withstanding reservations of these sorts, incrementalism has become a form of conventional wisdom. Statements to the effect that policy-making in Nigeria is incremental are common.

\subsection{Rational- Choice Theory}

The rational-choice theory, which is sometimes called social-choice, public-choice, or formal theory, originated with economists and involves applying the principles of micro-economic theory to the analysis and explanation of political behaviour (or nonmarket decision-making). It has now gained quite a few adherents among political scientists (Anderson, 1997).

Perhaps, the earliest use of rational-choice theory to study the political process is Anthony Downs"es Economic Theory of Democracy. In this influential book, Downs assumes that voters and political parties act as rational decision-makers who seek to maximise attainment of their preferences. Parties formulate whatever policies will win them most votes and voters, and seek to maximise the portion of their preferences that could be realised through government action. In attempting to win elections, political parties move toward the centre of the ideological spectrum to appeal to the greatest number of voters and maximise their voting support. Thus, rather than providing ,meaningful alternativese, parties will become as much alike as possible, thereby providing an ,echo rather than a choice (Downs, 1957).

This approach is based on economic principles such as the cost-benefit analysis. According to Henry:

One tries to learn all the value preferences extant in a society, assign each value a relative weight, discover all the policy alternatives available, know all the consequences of each alternative, calculate how the selection of any one policy will affect the remaining alternatives in terms of opportunity costs, and ultimately select the policy alternative that is the most efficient in terms of costs and benefits of social values (Henry, 2004:314). 
The rationalist model is conceptually quite simple. Policy-makers using it are expected to take the following steps:

$>$ Identify all the value preferences currently existing in a society.

$>$ Assign each value a relative weight,

> Discover all the alternative policies available to accomplish these values,

$>$ Know all the costs and consequences of each alternative policy,

$>$ Select the best alternative which is also the most efficient in terms of the costs and benefits of social values

The rationalist model deals with construction of public policies that ensure better public policies. It thus aims at improving public policy-making process. It is the opposite of incrementalism. Yehezkel Dror is a good representative of the rationalist model. How much of each value is equal to how much of each other value (Lindblom, 1980). For the above steps to be taken, the rational-choice theory according to Ikelegbe (1996) assumes the following:

That perfect information can be obtained for example, to objectively assess policy alternatives; that there is commonality of values and preferences particularly in the setting of goals and objectives, that the rational actor thinks of the greatest good of the greatest number as a guide to decision-making, that objectives and alternatives can be quantified and compared on a single monetary measure; that the conditions and parameters for the decision are static within the decision-making period. There is no doubt that these assumptions are simply not realisable in the real world situations, hence making the implementation of the model clearly impossible.

The rationalist model is appealing in its simplicity. But, there are problems that lie with its implementation. For instance, it lacks explicit concern for the political environment in which public policy must be carried out. Furthermore, according to Braybrooke and Lindblom (1964), the rational policy-making process, ideally, is based on knowledge of all of society"s value preferences, and their relative weight, all of the alternatives, all of the potential consequences (costs and benefits) of each policy alternative. The final selection must be that alternative that maximises the weighted value preference. The obvious limitation of this approach is its demand for knowledge (facts and information) not within the reach of mere mortals. The prospects of the successful application of this model in developing countries like Nigeria is very dim indeed given the paucity of data (in coverage and quality) needed for policy-making. Some scholars have argued that the average developing country has neither the technology, the resources nor the time to effectively employ this model in policy-making (Braybrooke and Lindblom, 1964)

Another serious objection to this model is its bias toward efficiency to the exclusion of other values such as equity and responsiveness. No doubt, rationalist model has its limitations but, it can be useful to policy-makers and administrators as a tool of policy output analysis.

Rational-choice studies of political behaviour are usually characterised by rigid and narrow assumptions, mathematical equations, abstractions, and remoteness from reality. Even William C. Mitchell, an early enlistee in the rational-choice movement, remarks that it appears in textbooks, rational-choice theory hardly involves government, politicians, bureaucrats, and interest groups. Little of the exposition...has anything to do with the fiscal or regulatory lives of the community or state (Mitchell, 1982: 99). A more positive view holds that in its pure form it is one, but only one, useful, partial explanation of politics (Weschler,1982:294).

Rational-choice theory both alerts us to the importance of self-interest as a motivating force in politics and policy-making, and provides a better understanding of decision-making processes. Many contend, however, that politics is not as devoid of altruism and concern for the public interest as the rationalchoice theorists assume. The adoption of good public policy, for example, is frequently a goal of members of the National Assembly. Public-interest groups, such as environmentalists, are motivated by more than immediate self-interest. 


\section{CONCLUSION AND RECOMMENDATIONS}

One cannot authoritatively say which of these theoretical approaches is the best or the most satisfactory as each approach focuses on different aspects of policy-making, and this seems more useful for understanding some situations or events than others. It seems wise not to be bound too dogmatically to one approach. A good rule for the policy maker is to be eclectic and flexible, and to draw from theories that seem most useful for the satisfactory and fair-minded description and explanation of policies. The objective explanation of political behaviour rather than the validation of one"s preferred theoretical approach should be the goal of political inquiry. Each of the theories discussed, if drawn upon skilfully and selectively, can contribute to a better understanding of policymaking.

\section{REFERENCES}

[1] Abdulsami, I. (1987). The Concept and Process of Public Policy. A paper presented at the national workshop for chief nursing officers, in Zaria, Wednesday $3^{\text {rd }}$ June, 1987.

[2] Anderson, J.E.(1997). Public Policy-Making: An Introduction $3^{\text {rd }}$ ed. Boston: Houghton Miffilin Company.

[3] Braybrooke, D. \&Lindblom, E. (1964).A Strategy of Decisions. Free Press of Glencoe, New York.

[4] Dlakwa, H.D. (2014). Concepts and Models in Public Policy Formulation and Analysis. Kaduna: PylamakServicies Ltd Nigeria.

[5] Downs, A. (1957). An Economic Theory of Democracy. New York: Harper and Row.

[6] Dye, T.R \& Zeigler, L.H. (1990).The Irony of Democracy. $8^{\text {th }}$ edition. Monterey, Califf: Books/Cole

[7] Hayes, M.T. (1992). Incrementalism and Public Policy. New York: Longman.

[8] Henry, N. (2004). Public Administration and Public Affairs. $9^{\text {th }}$ ed. New Delhi: Prentice Hall. [9]

[9] Latham,E. (1965). The Group Basis of Politics, New York: Octagon Books

[10] Mitchell, W.C. (1982). Textbook Public Choice: A Review Essay. Public Choice, XXVIII.

[11] Mosca, G. (1939). The Ruling Class, (Translated by Hannah D. Kahn), New York: McGrow-Hill Book Company.

[12] Obi, E.A, Nwachukwu, C.L. and Obiora, A.C. (2008).Public Policy Analysis and Decision Making. Onitsha: Bookpoint Educational Ltd.

[13] Simon, H.A. (1957). Administrative Behaviour: A Study of Decision-Making Processes in Administrative Organisation. $2^{\text {nd }}$ ed. New York: The Macmillian Company.

[14] Weischler, L.F. (1982). Methodological Individualism in Politics. Public Administration Review, XL III, May/June.

Citation: Prof. Adam A. Anyebe. " An Overview of Approaches to the Study of Public Policy." International Journal of Political Science (IJPS), vol 4, no.1, 2017, pp.08-17. doi:http://dx.doi.org/10.20431/24549452.0401002.

Copyright: () 2017 Authors. This is an open-access article distributed under the terms of the Creative Commons Attribution License, which permits unrestricted use, distribution, and reproduction in any medium, provided the original author and source are credited. 